Supplement of Clim. Past, 12, 1519-1538, 2016

http://www.clim-past.net/12/1519/2016/

doi:10.5194/cp-12-1519-2016-supplement

(C) Author(s) 2016. CC Attribution 3.0 License.

(c) (i)

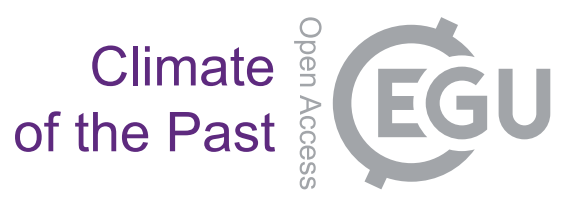

Supplement of

\title{
The PRISM4 (mid-Piacenzian) paleoenvironmental reconstruction
}

\section{Harry Dowsett et al.}

Correspondence to: Harry Dowsett (hdowsett@usgs.gov)

The copyright of individual parts of the supplement might differ from the CC-BY 3.0 licence. 

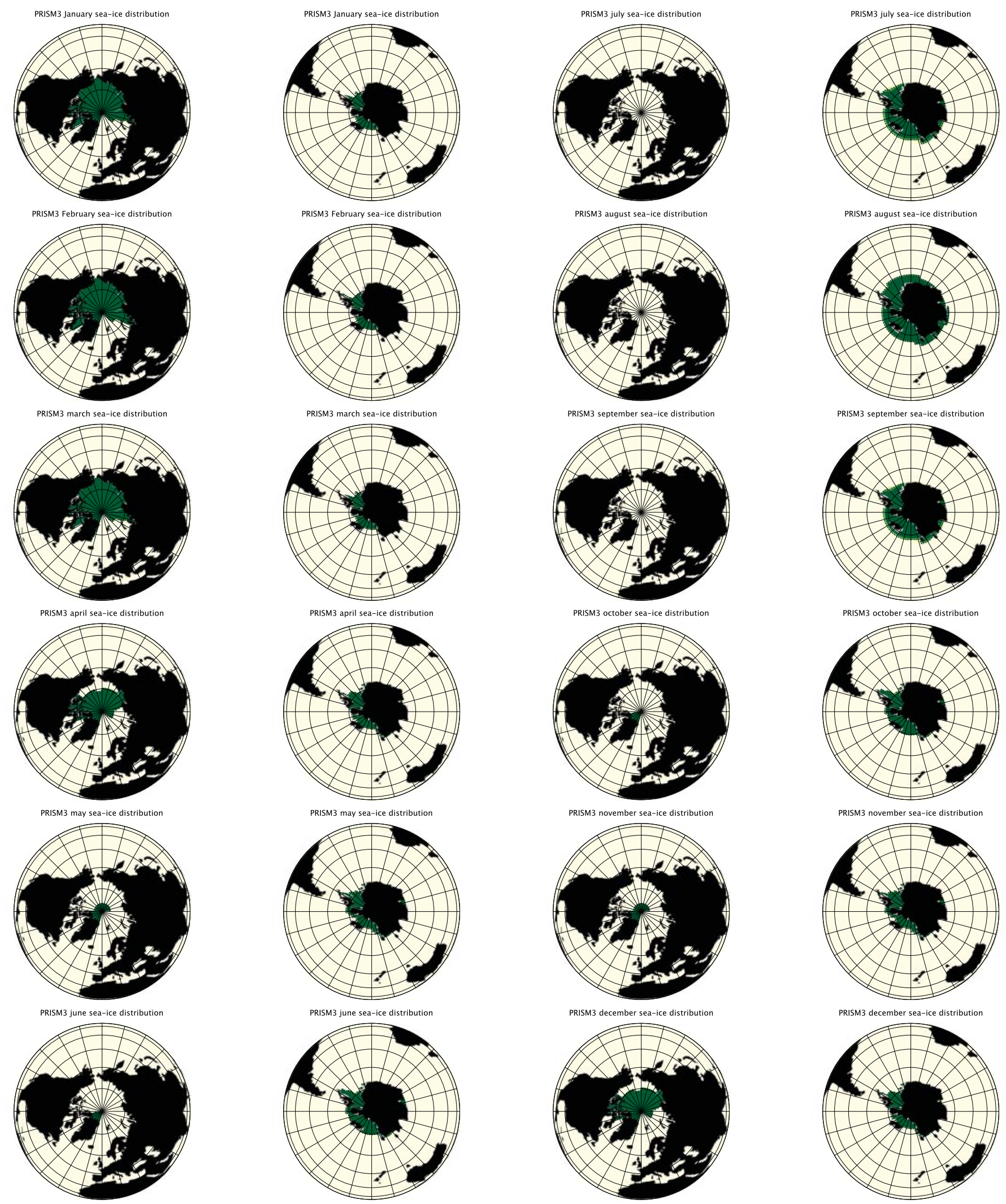

Figure S1. PRISM3 monthly sea-ice distribution. 


\section{ODP Site 982}

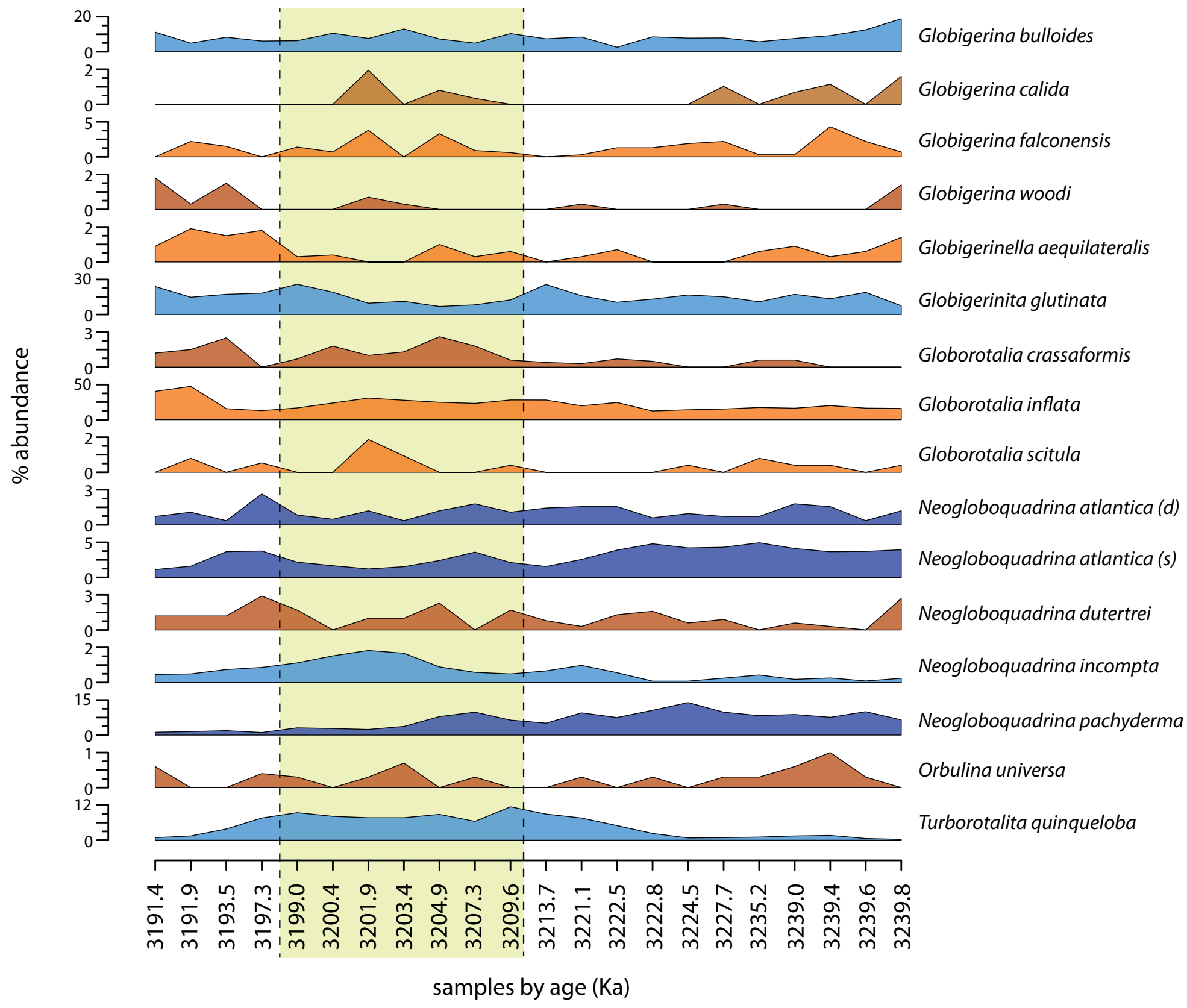

Figure S2. Planktonic foraminifer abundance data for part of North Atlantic ODP Site 982. Yellow vertical band indicates position of MIS KM5c. Color of abundance curves indicates taxon is a primary contributor to the Polar (dark blue), Subpolar (light blue), Subtropical (orange), or other (brown) assemblage. 


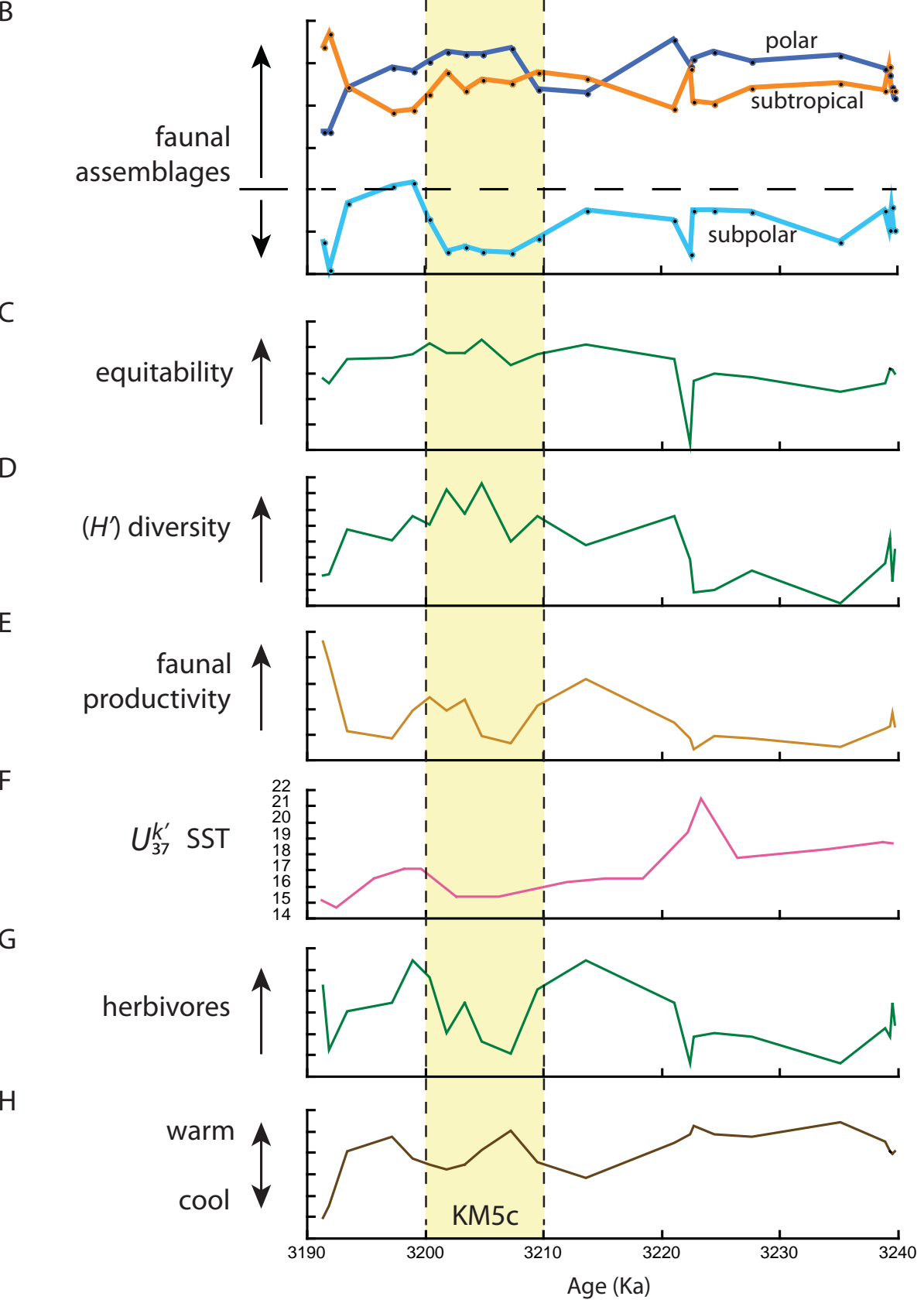

Figure S3. Example of palaeoenvironmental indicators for ODP Site 982. Vertical yellow band indicates position of MIS KM5c, chosen as a target for data-model comparison by PlioMIP2 (Haywood et al., 2016). (A) Oxygen isotope data from Khelifi et al. (2012). (B) Relative contributions to the fauna from polar (blue), sub-polar (light blue) and subtropical (orange) assemblages. (C) Biodiversity using the Equitability Index. (D) Biodiversity using Shannon diversity $\left(H^{\prime}\right)$. (E) Faunal productivity index based upon relative abundance of select taxa. (F) Alkenone SST. (G) Relative abundance of hebivorous planktic foraminifers. $(H)$ Relative change in taxa indicative of warmer water temperatures. An understanding of direction of change, variability and processes can be generated from data such as these. 
Table S1. Color and textures for soil orders used in PRISM4 (Pound et al., 2014).

\begin{tabular}{lllc}
\hline Soil & Color & Texture & Albedo \\
\hline Gelisol & Intermediate & Medium & 0.17 \\
Histosol & Dark & Fine & 0.11 \\
Spodosol & Intermediate & Medium/Coarse & 0.17 \\
Oxisol & Intermediate & Fine/Medium & 0.17 \\
Vertisol & Dark & Fine & 0.11 \\
Aridisol & Light & Coarse & 0.35 \\
Ultisol & Intermediate & Fine/Medium & 0.17 \\
Mollisol & Dark & Medium & 0.35 \\
Alfisol & Intermediate & Medium & 0.17
\end{tabular}

\section{Supplement References}

Khelifi, N., Sarnthein, M., and Naafs, B. D. A.: Technical note: Late Pliocene age control and composite depths at ODP Site 982, revisited, Climate of the Past, 8, 79-87, 10.5194/cp-8-79-2012, 2012.

Pound, M. J., Tindall, J., Pickering, S. J., Haywood, A. M., Dowsett, H. J., and Salzmann, U.: Late Pliocene lakes and soils: a global data set for the analysis of climate feedbacks in a warmer world, Climate of the Past, 10, 167-180, 10.5194/cp-10-167-2014, 2014.

Haywood, A. M., Dowsett, H. J., Dolan, A. M., Rowley, D., Abe-Ouchi, A., OttoBliesner, B., Chandler, M. A., Hunter, S. J., Lunt, D. J., Pound, M., and Salzmann, U.: The Pliocene Model Intercomparison Project (PlioMIP) Phase 2: scientific objectives and experimental design, Climate of the Past, 12, 663-675, 10.5194/cp-12-663-2016, 2016. 